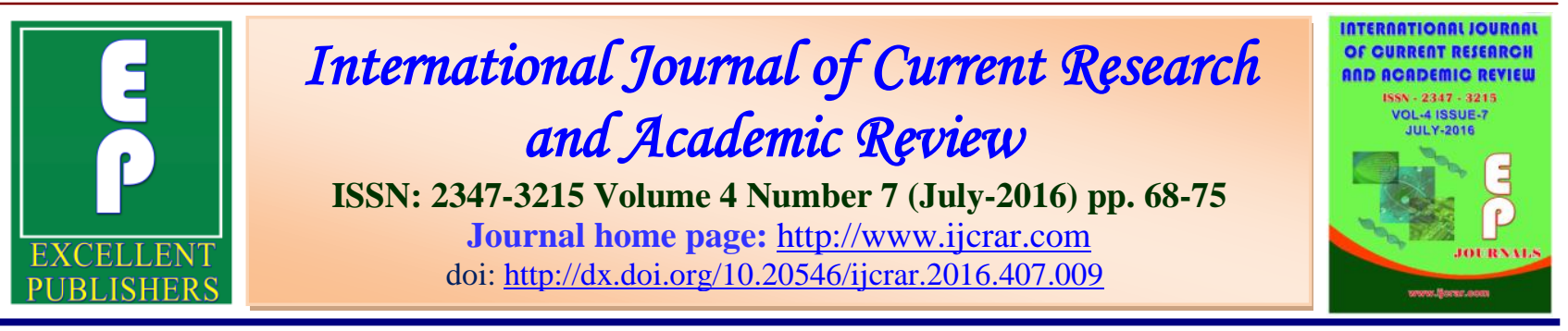

\title{
The Relationship between Internet Addiction and Depression in Male High School Students in Gifted and State Schools of Khorramabad in 2014-2015
}

\author{
Foroogh Riahi ${ }^{1}$, Ashraf Tashakori ${ }^{2}$ and Amir Akhashi ${ }^{3 *}$ \\ ${ }^{1}$ Assistant Professor, Department of Psychiatry, Golestan hospital, Ahvaz Jundishapur \\ University of Medical Sciences, Ahvaz, Iran \\ ${ }^{2}$ Associate Professor, Department of Psychiatry, Golestan hospital, Ahvaz Jundishapur \\ University of Medical Sciences, Ahvaz, Iran \\ ${ }^{3}$ Student of General Medicine, Department of Medicine, Student Research Committee, Ahvaz \\ Jundishapur University of Medical Sciences, Ahvaz, Iran \\ *Corresponding author
}

\begin{tabular}{|l|l|}
\hline \multirow{4}{*}{$\begin{array}{l}\text { KEYWORDS } \\
\text { Addiction, } \\
\text { Depression, }\end{array}$ Students. } & A B S T R A C T \\
\cline { 2 - 3 } & $\begin{array}{l}\text { In the past few years science and technology development is incredibly } \\
\text { accelerated. The Internet is also not an exception. In fact, the Internet can be } \\
\text { considered as the greatest technology designed, engineered and implemented } \\
\text { by human being. According to the importance of depression and the Internet } \\
\text { addiction the present study is aimed at studying the relationship between the } \\
\text { internet addiction and depression in male high school students in gifted and } \\
\text { state schools of Khorramabad. The present study is a descriptive-correlational } \\
\text { research. In this project 64 samples are obtained and then in the target } \\
\text { population by the distribution of the Internet addiction and Beck depression } \\
\text { questionnaires the level of the Internet addiction and depression prevalence in } \\
\text { the sample population is obtained. For the analysis of this study spss software } \\
\text { version 20 is used. Correlation and regression methods are applied to analyze } \\
\text { the data. The prevalence of Internet addiction in normal users is 1.6\% (1), } \\
90.6 \% \text { (58) had mild Internet addiction, 7.8\% (5) had moderate Internet } \\
\text { addiction and no one had severe addiction to the internet. In regression } \\
\text { analysis given the calculated r (0.721) and the level of significance (0.000), } \\
\text { there is correlation between internet addiction and depression and it can be } \\
\text { said that there is a direct relationship between these two variables. According } \\
\text { to the results of the present study it can be concluded that Internet addiction } \\
\text { exists in students and to prevent risks and complications in students, it is } \\
\text { necessary to pay attention to health considerations. }\end{array}$
\end{tabular}

\section{Introduction}

In the past few years science and technology development is incredibly accelerated. The Internet is also not an exception. In fact, the
Internet can be considered as the greatest technology designed, engineered and implemented by human being (Asadi et al., 
2011). Statistics provided by the National Internet Development Management in 2010 shows that Internet influence in Iran is has been $32 \%$ (Asadi et al., 2011). The unique characteristics of the Internet including ease of access to it, being available round the clock, the simplicity, low cost, anonymity of its users and other features have led to its significant popularity around the world. These features, in addition being considered as the Internet advantages, are counted among its disadvantages as well. One of the problems that the Internet has created is the internet addiction that has very dangerous mental and behavioral effects on the users (Khajehmougahi et al., 2010). Using the Internet wastes the precious time that one can use to spend with family and friends which leads to creating small community groups, higher levels of loneliness and symptoms of stress and depression (Griffiths, 2010). In recent years the studies have reported the prevalence of Internet addiction between 0.3 and $22 \%$ (2). Major addiction criteria that should last at least 20 months include: tolerance, withdrawal symptoms, forced to use the Internet to reduce or prevent Withdrawal symptoms, overuse of the internet more than the time intended, reduction of social, occupational and recreational activities and the risk of loss of job, education and employment opportunities due to excessive use of the Internet (Fitzpatrick, 2008). Depression is one of the most common psychiatric and mood disorders among people in the world the prevalence of which is between 8 and 20\% (Chong et al., 2001). Depression is a disorder characterized by loss of energy and interest, guilt, difficulty in concentration, loss of appetite and thoughts of death and suicide and it is associated with changes in activity level, cognitive abilities, speech, sleep, appetite and other biological rhythms. Depression leads to impaired job performance, social and interpersonal relationships (Akiskal, 2001). Studies show that there is a significant relationship between the increased use of the Internet and sense of loneliness among adolescents and young adults (Sanders et al., 2007). Results of studies conducted in the United States show that using the internet among the aduslts id more than any other age group (Bullen et al., 2000). Therefore, according to the importance of depression and the Internet addiction the present study is aimed at studying the relationship between the internet addiction and depression in male high school students in gifted and state schools of Khorramabad.

\section{Materials and Methods}

The present study is a descriptivecorrelational research. In this project 64 samples are obtained and then in the target population by the distribution of the Internet addiction and Beck depression questionnaires the level of the Internet addiction and depression prevalence in the sample population is obtained and then using the statistical method the relationship between the Internet addiction and depression is measured.

In this study, the questionnaires were completed as self-report by the students. Kimberley Yang 20 item test is used to measure Internet addiction. In this test the respondent should rate the items based on five point Likert scale including never, rarely, sometimes, often and always. The test scores range from 0 to 100 that the higher score indicates a greater dependence on the Internet and more severe problems created for the person as the result of the excessive use of it. To evaluate the resulting score, Yang instructions are used which means that the score between 20 and 49 indicates normal user, score between50 and 79 reflects the users at risk and the score 
between 80 and 100 indicates addicted users. In Sweden in a study the Cronbach's alpha of $95 \%$ is achieved (Widyanto, 2004).

Beck Depression Inventory (BDI) has 13 four option questions which is designed based on Likert scale. The items are scored from zero to 3 ; thus the scores range from zero to 39 (10). Persons with the score of 0 to 4 are in the group without depression, the score of 5-7 indicates minor depression score, the score of 8-15 indicates average score and the score of 16 or higher indicates severe depression. For the analysis of this study spss software version 20 is used. Correlation and regression methods are applied to analyze the data.

\section{Results and Discussion}

In this study, the frequency of depression according to the groups without mild and moderate depression is 26 subjects $(40.6 \%)$, 21 subjects (32.8\%), 17 subjects $(26.6 \%)$ while no person had severe depression.

The prevalence of Internet addiction in normal users is $1.6 \%$ ( 1 person), $90.6 \%$ (58 persons) had mild Internet addiction, $7.8 \%$ (5 persons) had moderate Internet addiction and no one had severe addiction to the internet.

The average score of students who had depression was $5.25 \pm 3.695$ with the lowest score zero and the highest score 15 and the average score of students who had internet addiction was $37.05 \pm 9.671$ with the lowest score of 20 and the highest score of 59.

Kolmogorov-Smirnov test was used to normalize the data and given that the results of the data distribution were normal, the parametric tests were used to test the hypotheses. (Table 1)
In regression analysis given the calculated $\mathrm{r}$ (0.721) and the level of significance (0.000), there is correlation between internet addiction and depression and it can be said that there is a direct relationship between these two variables. Therefore the data showed that by increasing the value of Internet addiction depression variable values can be increased. (Table 2)

According to Table 3 the value of $\mathrm{R}$ refers to the simple correlation between the two variables; in other words it refers to the intensity of the correlation between two variables that is significant between Internet addiction and depression.

Also the value of $\mathrm{R} 2$ indicates that in this test the Internet addiction variable can explain 52 percent of variance of depression, which is a significant amount. One-way analysis of variance and covariance analysis indicate the statistical significance of the regression model the significance of which is less than 0.05 which indicates that the regression model of the present study is significant (Table 3 ).

The internet before being available to the public was considered as a means for confidential correspondence to obtain relations. Then it grew fast and converted into an essential means in our lives. Many academic studies have been done to analyze the impact of new technologies on mental health and how to create disorder or mental distress (Omidvar, 2003).

In fact, Internet addiction is a disorder of impulse control and maladaptive pattern of Internet use that leads to clinically significant distress or impairment and creates psychological, school and occupational problems in the individual's life the prevalence of which is within the age of 15 to 19 which is greater than other age 
groups. So that clinicians have reported cases of the disorder in their clinics and this disorder is considered as a new form of addiction in recent years in the fields of psychology, psychiatry, sociology, and other science areas. Internet addiction is a problem that is seen in different cultures and societies. The prevalence of this problem has led to the identification and investigation of the causes, consequences and complications by experts and researchers (lmann, 2001).

Results obtained from the data analyses of this study indicated that there is a significant relationship between depression and Internet addiction. Yang (Young, 1999) and other psychologists believe that the excessive use of the Internet may be dangerous for the mental and physical health of the individual. Internet addiction disrupts a person's adaptive function and if a person is addicted to the Internet, his functions become maladaptive (Kraut et al., 1998). The results of this research are consistent with Kariminia (Favaretto et al., 2004) and HosseinZadeh (Yen et al., 2007) who believe that the internet addiction is associated with symptoms such as anxiety, depression, irritability, restlessness, obsessive thoughts or fantasies about the internet. On the other hand, while relations of these people (especially children and adolescents) are increased in the virtual world, the scope of their relations in the real world is reduced. Moreover, there is also the possibility of reduced education performance.

Also consistent with these results Kraut et al., (2010) in a two-year research on the Internet users concluded that the excessive use of the Internet has reduced the family relation and participate in local social circles. In addition, participants in this study had developed isolation and depression.
Favaretto et al., (2000) have concluded that there is a significant relationship between hours of Internet use and mental health scores. This means that there is a clear link between excessive use of the Internet and psychological disorders.

In a general conclusion of the other studies it became clear that depression is correlated with the internet addiction and these studies are consistent with the research results. There is a possibility that the conflicting results reported in other studies indicate the lack of significant relationship between each of depression, anxiety, stress and social phobia are due to different reasons such as analyzing this relationship in a particular population, sample size of population, the use of non-standard questionnaires or nonrecognition of some of clinical symptoms.

In this study the overall prevalence of depression based on the normal, mildly and moderate depressed groups are 26 subjects (40.6\%), 21 subjects (32.8) and 17 subjects (26.6\%). However no one had severe depression. The prevalence of Internet addiction in normal users is $1.6 \%$ (1 person), $90.6 \%$ (58 persons) had mild Internet addiction, $7.8 \%$ (5 persons) had moderate Internet addiction and no one had severe addiction to the internet.

The results of Toyuri et al., (2015) showed that 20.5 percent of students had mild Internet addiction and $5.8 \%$ of the students had severe addiction to the internet and the study of Dargahi and Razavi reported the mild and severe Internet addiction ad 26 and $4 \%$. In the present study most students had mild depression which is consistent with Hassan Zadeh et al., (2012) who showed that $0.4 \%$ of students were normal, 82 percent of university students had mild depression, $17.2 \%$ of the students had medium depression and 0.4 percent had 
Int.J.Curr.Res.Aca.Rev.2016; 4(7): 68-75

severe internet addiction. Also the prevalence of severe Internet addiction was $5.4 \%$ in the study conducted by Pallanti et al., (2013) on high school students in Italy. But Yu and Shek (2013) reported different outcomes for Hong Kong adolescent in which the prevalence of severe Internet addiction was $26.7 \%$. However, recent studies have shown that the prevalence of severe Internet addiction in adolescents in different cultures and societies has a wide variation between 1.5 and $30 \%$ which is increasing (Kim et al., 2006; Jafari, 2012). The difference with the present study might be due to poor access to the Internet and how to use the Internet by students.

Table.1 Normal distribution of test data

\begin{tabular}{|c|c|c|c|}
\hline Variables & Values & Degree of freedom & Significance \\
\hline Internet addiction & 0.852 & 64 & 0.463 \\
\hline Depression & 0.966 & 64 & 0.308 \\
\hline
\end{tabular}

Table.2 Results of correlation between internet addiction and depression

\begin{tabular}{|c|c|c|}
\hline Variables & Correlation coefficient & Significance \\
\hline Internet addiction & 0.721 & 0.000 \\
\hline Depression & 0.721 & 0.000 \\
\hline
\end{tabular}

The correlation is significant at 0.01 .

Table. 3 Results of one-way analysis of variance and covariance between the dependent variable and Internet addiction

\begin{tabular}{|c|c|c|c|c|c|c|c|}
\hline & $\begin{array}{c}\text { correlation } \\
\text { coefficient } \\
(\mathbf{R})\end{array}$ & $\begin{array}{c}\text { The square of } \\
\text { the correlation } \\
\text { coefficient } \mathbf{( R}^{\mathbf{2}}\end{array}$ & $\begin{array}{c}\text { Total } \\
\text { square }\end{array}$ & $\begin{array}{c}\text { Degrees of } \\
\text { freedom }\end{array}$ & $\begin{array}{c}\text { Mean } \\
\text { square }\end{array}$ & $\begin{array}{c}\text { F } \\
\text { Significa } \\
\text { nce (P) }\end{array}$ \\
\hline $\begin{array}{c}\text { Internet } \\
\text { addiction }\end{array}$ & 0.721 & 0.52 & 447.141 & 1 & 447.141 & 67.148 & 0.000 \\
\hline
\end{tabular}

The results of Ozturk et al., (2009) and Kim et al., that have conducted their studies on Turkish and Korean students have shown significant relationship between anxiety, depression and internet addiction.

Consistent with these results, the comparison of the prevalence of depression in terms of the internet addiction indicates the high and significant prevalence of depression in students with the internet addiction that is consistent with Ja'fari et al. Also in explaining these results it can be mentioned that on the one hand it seems that people with anxiety stress and depression use the internet to escape from these disorders and find a replacement for the life devoid of happiness and these conditions provide the conditions for their greater dependence on the Internet and on the other there is a possibility that these disorders are the result of internet addiction such that people who are addicted to the Internet are subject to the disorders due to the dependency and change in their lifestyle or if they have no access to the internet, they might feel anxiety, stress and depression. 


\section{Conclusion}

Perhaps in today's world, the internet and computer technologies are considered the most effective tools provided that they are used adequately by proper training and guidelines not to the extent that they impair people's physical and mental health. So it can be said that Internet addiction is considered by the researchers as a new form of addiction in recent years. According to the results of the present study it can be concluded that Internet addiction exists in students and to prevent risks and complications in students, it is necessary to pay attention to health considerations. It is recommended to address the students' internet addiction by collecting more statistical samples.

\section{Acknowledgment}

The authors hereby express their gratitude to the Ahvaz Jundishapur University of Medical Sciences for their supports and all of the colleagues who participated in this research. They also thank the Golestan Hospital Clinical Research Development Unit.

\section{References}

Akiskal, H. 2001. Mood disorder. In: Kaplan HI.; Sadock BJ. Comprehensive text book of psychiatry: From Williams \&Wilkins. Baltimore: USA, 7th ed. Vol 1, 1284-431.

Alavi, S.S., Maracy, M.R., Jannatifard, F., Eslami, M. 2010. The effect of psychiatric symptoms on the internet addiction disorder in Isfahan's University students. Scientific J. Hamadan University of Med. Sci., 17: 57-65.

Asadi, A.H., Zarei, F., Nasiri, A., Moraveji, S., Keikhani, R., Tehrani, H., et al.
2011. Digital Media and Health

Tehran: Asaresobhan; 2011. p. 5

Bullen, P. \& Harre, N. 2000. The Internet: Its Effects on fatety and behavior Implications for Adolescents, Department of Psychology, University of Auckland, November.

Campbell, A.J., Cumming, S.R., Hughes, I. 2006. Internet use by the socially fearful: addiction or theraoy? Cyberpsychol. Behav., 9: 69-81.

Chong, M.Y., Tsang, H.Y., et al. 2001. Community study of depression in old age in Tiavan: Prevalence, life event and sociodemographic correlates. $\mathrm{Br}$. J. Psaychiatry, 178(1): 29-35.

Dargahi, H., Razavi, S.M. 2007. Internet addiction and its related factors: a study of an Iranian population. Payesh, $J$. Iranian Institute for Health Sci. Res., 6(3): 265-72. [Persian]

Kariminia M. 2008. Adolescents and Internet addiction. Didar Ashena journal. 4(5).

Fitzpatrick, J.J. 2008. Internet addiction: Recognition and intervention. $J$. Psychiatr. Nurs., 22(9): 59-60.

Griffiths, M. 2010. Internet Abuse and Internet Addiction in the Workplace. J. Workplace Learning, 22(7): 463-72.

Hasanzadeh, R., et al. 2012. Internet Addiction among Islamic Azad university students. A General or Specific Problem? J. Basic. Appl. Sci. Res., 2(5): 5264-5271.

Jafari, N., Fatehizadeh, M. 2012. Investigation of the relationship between internet addiction and depression, anxiety, stress and social phobia among students in Isfahan University. Scientific J. Kurdistan University of Med. Sci., 17(4): 1-9.

Khajehmougahi, N., Alasvand, M. 2010. the Studying of Predictor Personality Variables of Internet Addiction. 
Scientific Med. J. Ahwaz University of Med. Sci., 9(4): 359- 66.

Kim, K., Ryu, E., Chon, M.Y., Yeun, E.J., Choi, S.Y., Seo, J.S., et al. 2006. Internet addiction in Korean adolescents and its relation to depression and suicidal ideation: a questionnaire survey. Int. J. Nurs. Stud., 43(2): 185-92.

Homayunifar M.R, et al. Internet addiction, its causes and consequences. Asrar journal. 9(4).

Lmann, R.J. 2001. Reasons for internet use and social anxiety, Pers Individ Dif Wang W. Internet dependency and psychosocial maturity among college students, Int. J. Human-Computer Studies, 55: 919-938.

Nastizai, N. 2009. The Relationship between general health and internet addiction. Zahedan J. Res. Med. Sci., 11(1): 5763.

Nathan, A.S., Toby, D.G., Paul, E.K.Jr, Uday, M., Khosla, S.L. 2000. McElroy. Psychiatric features of individuals with problematic internet use. J. Affect Disord., 57: 267-72.

Omidvar, A., sarami, A. [Internet addiction: description, ethnology, prevention, treatment and internet addiction disorder assessment indices] Persian. Mashad: Tamarind Press; 2003.

Ozturk, F.O., Ekinci, M., Ozturk, O., Canan, F. 2013. The relationship of affective temperament and emotionalbehavioral difficulties to internet addiction in Turkish teenagers. ISRN Psychiatry, 961-734.

Pallanti, S., Bernardi, S., Quercioli, L. 2006. The Shorter PROMIS Questionnaire and the Internet Addiction Scale in the assessment of multiple addictions in a high-school population: prevalence and related disability. CNS Spectr., 11(12): 966-74.
Saatchi, M., Kamkari, K., Aasgarian, M. 2010. [Psychological tests]. Tehran; Virayesh.

Sammis, J. 2008. Video game addiction and depression relates among video game player. A PHD dissertation. The Wright Institute.

Sanders, Ch.E., Tiffany, M., Field, M.D., \& Kaplan, M. 2000. The relationship of internet use to depression and social isolation among adolescents. Adolescence.

Shields, M.K., Beharman, R.E. 2000. Children and computer technology: Analysis and recommendations. The future of children and computer technology. Vol: $10 . \quad$ No: 2. Fall/winter.P:4-30.

Shek, D.T., Yu, L. 2012. Internet addiction phenomenon in early adolescents in Hong Kong. Scientific World J., 104304.

Sung, J., Lee, J., Noh, H.M., Park, Y.S., Ahn, E.J. 2013. Associations between the Risk of Internet Addiction and Problem Behaviors among Korean Adolescents. Korean J. Fam. Med., 34(2): 115-22.

Turi, A., et al. Prevalence of Internet Addiction and its relationship with anxiety, stress, and depression in intermediate students in Birjand city in 2014. J. Birjand University of Med. Sci., 22(1).

Widyanto, L., McMurran, M. 2004. The psychometric properties of the internet addiction test. Cyber Psychol. Behav., 7(4): 443-450.

Xu, J., Shen, L.X., Yan, C.H., Hu, H., Yang, F., Wang, L., et al. 2012. Personal characteristics related to the risk of adolescent internet addiction: a survey in Shanghai, China. BMC Public Health, 12: 1106. 
Int.J.Curr.Res.Aca.Rev.2016; 4(7): 68-75

Hosseinzadeh. Anxiety and reactions within the brain. Khorasan journal. 2011; 4(3).

Young, K.S. 1999. Cyber Disorders: The mental health 6- concern for the new millennium. Press for Cyber Psychology and Behavior of 107th APA Convention Available at www.net addiction.com, Accessed.

\section{How to cite this article:}

Foroogh Riahi, Ashraf Tashakori and Amir Akhashi. 2016. The Relationship between Internet Addiction and Depression in Male High School Students in Gifted and State Schools of Khorramabad in 2014-2015. Int.J.Curr.Res.Aca.Rev.4(7): 68-75. doi: http://dx.doi.org/10.20546/ijcrar.2016.407.009 